\title{
ECLAMC Study: prevalence patterns of hypospadias in South America: multi-national analysis over a 24-year period
}

Nicolás Fernández ${ }^{1,2}$, Jaime Pérez ${ }^{1}$, Pedro Monterrey ${ }^{3}$, Fernando A. Poletta ${ }^{4}$, Darius J. Bägli ${ }^{5}$, Armando J. Lorenzo ${ }^{5}$, Ignacio Zarante ${ }^{2}$

1 Departamento de Urología, Pontificia Universidad Javeriana, Departamento de Urología, Hospital Universitario San Ignacio, Bogotá, Colombia; ${ }^{2}$ Instituto de Genética Humana, Pontificia Universidad Javeriana, Bogotá, Colombia; ${ }^{3}$ Departamento de Matemáticas, Rosario University, Bogotá, Colombia; ${ }^{4}$ ECLAMC (Estudio Colaborativo Latinoamericano de Malformaciones Congénitas) at Centro de Educación Médica e Investigaciones Clinicas (CEMIC-CONICET), Buenos Aires, Argentina and Instituto Nacional de Genética Médica Populacional (INaGeMP), Rio de Janeiro, Brasil; ${ }^{5}$ Division of Urology, Department of Surgery, Hospital for Sick Children and University of Toronto, Toronto, Ontario

\section{ABSTRACT}

Objective: To evaluate prevalence trends of hypospadias in South-America it is essential to perform multicenter and multinational studies with the same methodology. Herein we present systematic data as part of an international multicenter initiative evaluating congenital malformations in South America over a 24-year period.

Materials and Methods: A nested case-control study was conducted using the Latin American Collaborative Study of Congenital Malformations (ECLAMC), between January 1989 and December 2012. Cases were stratified as isolated (IH) and non-isolated hypospadias (NIH). Global prevalence was calculated and discriminated by country. Associations between birth weight and gestational age, and NIH distribution by associated abnormality and severity of hypospadias, were analyzed.

Results: A total of 159 hospitals from six countries participated, reporting surveillance on 4.020.384 newborns. A total of 4.537 hypospadias cases were detected, with a global prevalence of 11.3/10.000 newborns. Trend analyses showed in Chile, Brazil and Uruguay a statistically significant increase in prevalence. Analysis of severity and associated anomalies did not to find an association for distal cases, but did for proximal $(\mathrm{RR}=1.64[95 \% \mathrm{CI}=1.33-2.03])$.

Conclusion: This is one of only a few Latin American multicenter studies reporting on the epidemiology of hypospadias in South America in the last two decades. Our data adds to evidence suggesting an increase in some countries in the region at different times. There were also variations in prevalence according to severity. This study adds to literature describing associated anomalies at a hospital-based level.

\section{ARTICLE INFO}

\section{Keywords:}

Hypospadias; Prevalence;

Epidemiology

Int Braz J Urol. 2017; 43: 325-34

Submitted for publication:

January 02, 2016

Accepted after revision:

April 24, 2016

Published as Ahead of Print:

November 02, 2016

\section{INTRODUCTION}

Despite being one of the most common congenital anomalies of the male external genitalia, after decades of research we still lack knowledge on the exact pathophysiology of hypospadias (13). In this regard, multiple authors have identified an increase in prevalence, information generated 
from studies in Europe and North America (4-6). Although a global phenomenon is plausible, there is a paucity of information on the trends and impact of this condition in many other parts of the world $(7,8)$.

To date, there have been few hospital-based studies with regional information including children from other parts of the World, such as Central and South America and Africa (1, 2, 9). To address this, herein we present data gathered in a systematic fashion as part of an international multi-center initiative evaluating congenital malformations in South America. We hypothesized that prevalence patterns should follow similar patterns to those presented in previous publications in other regions around the world. The aim of the present study was to analyze trends and conduct an epidemiologic description over a 24-year period using information from the Latin-American Collaborative Study of Congenital Malformations (ECLAMC) (10).

\section{MATERIALS AND METHODS}

\section{Database description}

The ECLAMC initiative is a multicenter international collaboration designed to identify associated risk factors and potential causes of congenital anomalies (CA). The data collection methodology has previously been reported (10). For the purpose of the present analyses, we followed a nested case-control design (10), analyzing information forwarded from each participating center to the ECLAMC headquarters. Retrospective review of data from the ECLAMC database encompassed information gathered between January 1989 and December 2012. We focused our evaluation on newborns diagnosed with hypospadias.

Data collection and quality management

Data collection followed a standardized methodology for the entire study period.

Population: Briefly, each participating center conducted daily surveillance of all newborns looking for a detectable CA. For every detected case, the following information was collected: mother's demographic data, prenatal and delivery information, and exposure to medications and toxic substances during pregnancy. Personnel trained specifically in the ECLAMC methodology at each institution conducted these assessments. For every enrolled case, the immediate next same-gender newborn was included as a control, collecting the same information.

Following approval of the study protocol by the ECLAMC board of directors and institutional ethics boards, information about all registered newborns with hypospadias and controls was gathered from the following countries: Argentina, Brazil, Bolivia, Chile, Colombia, Costa Rica, Ecuador, Paraguay, Peru, Uruguay and Venezuela. We excluded information from countries with incomplete registries, defined as those with more than 40\% missing information in the database, and from those that failed to provide evidence of a continuous surveillance process over the study's timeframe.

\section{Inclusion criteria}

Isolated hypospadias (IH) cases were strictly defined as male newborns with an ectopic urethral meatus located along the ventral aspect of the penis and no other CA. Depending on location, these were further categorized as glanular, coronal, penile and scrotal. (Perineal and penoscrotal were included in this last category) (11). There were 29 megameatus intact prepuce variant cases and for that reason these patients were included in the glanular hypospadias group. Associated scrotal findings were also recorded. Newborns with associated anomalies were separately labeled as non-isolated hypospadias (NIH) cases. Each one of the associated anomalies was described in detail following the ECLAMC protocol for each of the different anomalies.

\section{Statistical analyses}

Global prevalence analysis: For each center prevalence rates were registered annually during study period then aggregated and individualized (per country) hypospadias prevalence patterns over time were calculated, testing the null hypothesis of a zero slope curve as evidence of lack of increase over time. Annual rate changes were estimated from the slope of a regression line drawn through the observed values. The signifi- 
cance and linearity of the rate trend were tested following the Cochran and Armitage test to assess for gradient in proportions from several independent, quantitatively ordered samples (as reported by Fleiss) (12). This analysis was based on the formula:

Rate=Intercept + slope * year (based on $y=b+m x$; where $\mathrm{m}=$ slope, and $\mathrm{b}=$ intercept).

Exclusion of glanular cases prevalence analysis: To confirm the significance of the initial global trend we adjusted by hypospadias severity (exclusion of glanular cases) and performed a second analysis following a similar methodology as described before. We analyzed the population for trends, stratified based on country and hypospadias severity, as previously defined. In addition, this stratification was further evaluated for potential associations with $\mathrm{NIH}$, reported as relative risks.

Secondary analysis adjusted for periods of time and countries: In order to give more support to the analysis, we verified our results and minimized biases by performing a secondary analysis for prevalence trends using a Poisson regression analysis, dividing the results for each country into periods of 5 years and adjusting for the effect of each hospital in the results. This was performed to reduce the effect of hospital registries in the results. The same analysis was performed after excluding all glanular cases for the reason mentioned above.

Associated anomalies analysis: For all NIH cases we analyzed the distribution of each associated abnormality and distribution based on hypospadias severity. In order to standardize assessment, we segregated associated anomalies by affected systems, i.e. genitourinary tract (GUT), gastrointestinal tract (GIT), limbs, facial anomalies (FA), cardiovascular (CV) and nervous system (CNS), abdominal wall (ABD), and others.

Lastly, we evaluated the impact of birth weight and maternal age in cases compared to controls using a Student T test. All analyses were conducted using Excel ${ }^{\mathrm{TM}}$.

\section{RESULTS}

During the study period, a total of 192 centers in 12 countries supplied data to the centralized information center. After excluding countries with missing or incomplete information the final analysis comprised 159 hospitals from six South American countries.

Global population analysis: Between 1989 and 2013, the above-mentioned centers conducted surveillance on 4.020.384 newborns, detecting a total of 4.537 hypospadias, and resulting in a global prevalence of 11.3 per 10.000 newborns. Trend analysis demonstrated a global increase in annual prevalence of 0.2 hypospadias cases per 10.000 newborns per year $(p<0.0001)$. This translates into a 3.3\% increase over the study period (Figure-1).

The distribution of hypospadias cases by severity is shown in Table-1. A total of $82.2 \%$ of the hypospadias cases were isolated, with the remaining $17.8 \%$ being associated with other reported anomalies. Although we found an increase in prevalence trends for distal hypospadias, these failed to reach statistical significance (1.3\% in 24 years).

Analysis of the severity distribution and presence of associated anomalies during the entire study period revealed no association with distal cases (glanular hypospadias RR=0.93 [95\% CI=0.85-1.01], coronal hypospadias $\mathrm{RR}=0.84$ [95\% $\mathrm{CI}=0.76-0.94]$ ) whereas more proximal cases (penile hypospadias $\mathrm{RR}=1.64$ [95\% CI=1.33-2.03], scrotal hypospadias $\mathrm{RR}=2.49$ [95\% CI 1.80-3.47]) were significantly associated with other congenital anomalies.

When specifically evaluating $\mathrm{NIH}$ cases, we identified 809 patients with 1117 associated anomalies. On average there were 1.7 anomalies per NIH patient. The most common associated anomaly was cryptorchidism, representing $15.3 \%$ of associated anomalies, followed by minor facial anomalies (7.52\%). Distribution analysis showed that after excluding minor facial anomalies, the most commonly affected system was the GUT (23.3\%), followed by major FA (20.5\%), CV (10\%), CNS (8.7\%), limbs (8.2\%), 
Figure 1 - Global prevalence trend of patients diagnosed with hypospadias at birth in 6 different countries in South America. The increasing trend is statistically significant. $(\mathrm{p}<0.001)$.

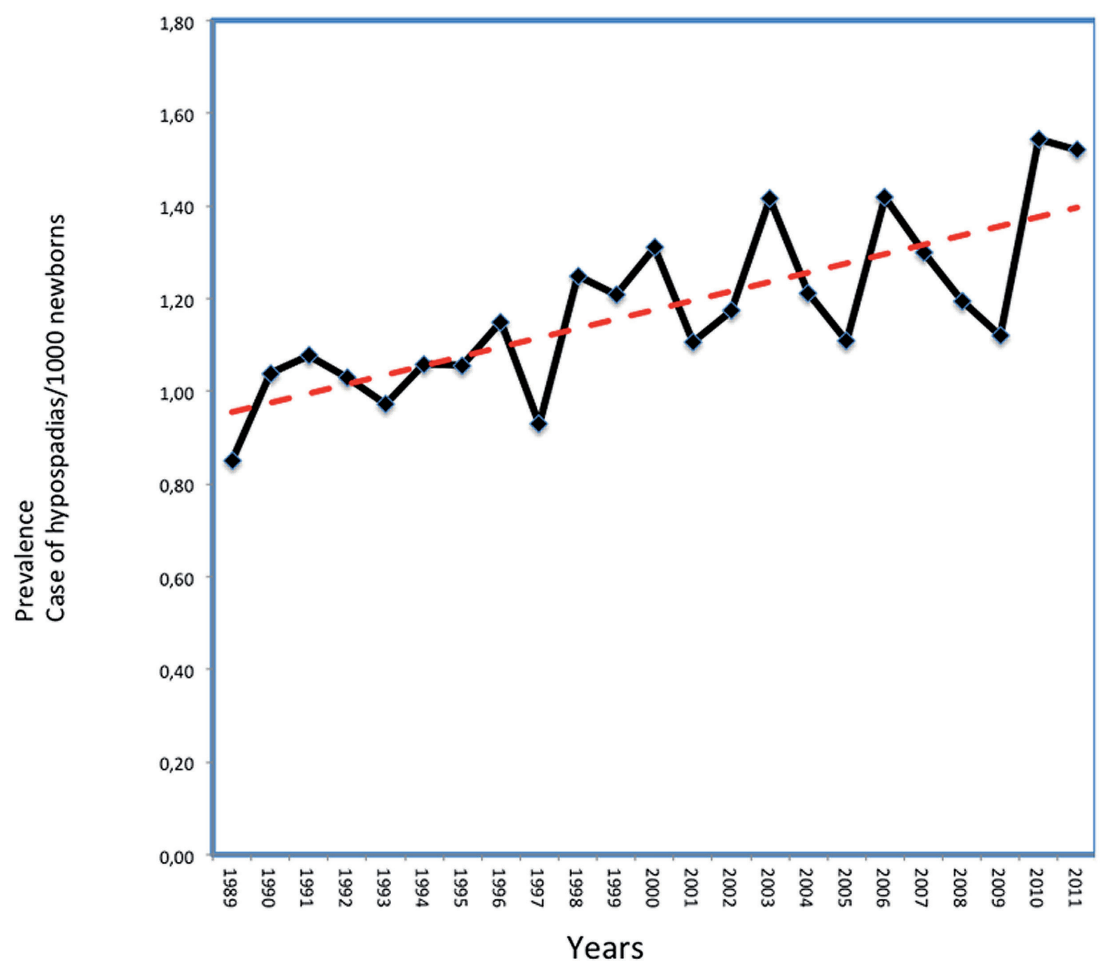

GIT (6.3\%), other anomalies (6\%), and ABD (3.2\%) Table-2. We detected $13(1.6 \%)$ cases of Down's syndrome associated with hypospadias (nine glanular, three coronal and two penile). There were eight $(0.7 \%)$ cases associated with Edwards' syndrome. VACTERL association was diagnosed in five $(0.4 \%)$ cases Table- 2 .

The average birth weight of hypospadias cases was 2914.2+/-621.6 grams, compared with
$3251.1+/-753.6$ for controls $(\mathrm{p}<0.001)$. These results were adjusted for gestational age. The average age of the mother at the time of delivery was 26.2 years old $(S D+/-5.6 y)$ for hypospadias cases and 26.3 years old (SD+/-7.4 y) for controls $(\mathrm{p}=0.27)$.

Secondary adjusted analysis: Chile, Brazil and Uruguay showed a statistically significant increase in prevalence, while Argentina,

Table 1 - Distribution of hypospadias according to severity and association with other anomalies.

\begin{tabular}{lcccc}
\hline \multirow{2}{*}{ Type of Hypospadias } & \multicolumn{1}{c}{ Total } & Isolated & Non-Isolated & \multirow{2}{*}{ RR $(95 \% \mathrm{Cl})$} \\
\cline { 2 - 4 } & $(\mathrm{N}-\%)^{1}$ & $(\mathrm{~N})$ & $(\mathrm{N}-\%)^{2}$ & \\
\hline Glanular & $2189(48.3 \%)$ & 1822 & $376(16.8 \%)$ & $0.93(0.85-1.01)$ \\
Coronal & $1800(39.7 \%)$ & 1521 & $279(15.5 \%)$ & $0.84(0.76-0.94)$ \\
Penile & $388(8.6 \%)$ & 286 & $102(26.3 \%)$ & $1.64(1.33-2.03)$ \\
Scrotal & $148(3.4 \%)$ & 96 & $52(35.1 \%)$ & $2.49(1.80-3.47)$ \\
\hline Total & $\mathbf{4 5 3 4 ( 1 0 0 \% )}$ & $\mathbf{3 7 2 5}$ & $\mathbf{8 0 9}$ & \\
\hline
\end{tabular}

$1=$ Percentage of each type of total; ${ }^{2}=$ Percentage of Non-isolated cases of total cases in each type. 
Table 2 - Five most common associated anomalies by system and its distribution according to the severity of hypospadias.

\begin{tabular}{|c|c|c|c|c|c|c|c|}
\hline Systems & Malformation & Glanular & Coronal & Penile & Scrotal & Total & Percent \\
\hline Genito-urinary tract & Cryptorchidism & 64 & 58 & 34 & 15 & 171 & 15.31 \\
\hline \multirow[t]{4}{*}{$(23.8 \%)$} & Hydronephrosis & 7 & 9 & 5 & 2 & 23 & 2.06 \\
\hline & Renal Agenesis & 10 & 5 & 1 & 0 & 16 & 1.43 \\
\hline & Hydrocele & 8 & 5 & 0 & 0 & 13 & 1.16 \\
\hline & Inguinal Hernia & 7 & 4 & 1 & 1 & 13 & 1.16 \\
\hline Facial & Cleft lip/palate & 33 & 31 & 5 & 8 & 77 & 6.89 \\
\hline \multirow[t]{4}{*}{$(20.5 \%)$} & Micrognathia & 22 & 21 & 7 & 4 & 54 & 4.83 \\
\hline & Low ear implantation & 19 & 18 & 5 & 2 & 44 & 3.94 \\
\hline & Preauricular pit & 20 & 17 & 3 & 0 & 40 & 3.58 \\
\hline & Microtia & 5 & 8 & 1 & 0 & 14 & 1.25 \\
\hline Cardiovascular & Ventricular septal defect & 16 & 9 & 1 & 6 & 32 & 2.86 \\
\hline \multirow[t]{4}{*}{$(10.0 \%)$} & Single umbilical artery & 7 & 10 & 4 & 4 & 25 & 2.24 \\
\hline & Auricular septal defect & 9 & 6 & 3 & 2 & 20 & 1.79 \\
\hline & Valvular anomalies & 5 & 2 & 5 & 0 & 12 & 1.07 \\
\hline & Patent Ductus arteriosus & 1 & 3 & 3 & 0 & 7 & 0.63 \\
\hline Central Nervous system & Hydrocephalus & 32 & 17 & 15 & 9 & 73 & 6.54 \\
\hline \multirow[t]{2}{*}{$(8.7 \%)$} & Spina bifida & 9 & 3 & 1 & 2 & 15 & 1.34 \\
\hline & Other & 3 & 4 & 1 & 1 & 9 & 0.81 \\
\hline Limbs & Polydactyly & 19 & 11 & 1 & 1 & 32 & 2.86 \\
\hline \multirow[t]{4}{*}{$(8.2 \%)$} & Hip Displasia & 8 & 7 & 1 & 0 & 16 & 1.43 \\
\hline & Clinodactyly & 3 & 6 & 3 & 0 & 12 & 1.07 \\
\hline & Arthrogryposis & 4 & 2 & 2 & 1 & 9 & 0.81 \\
\hline & Camptodactyly & 3 & 1 & 0 & 0 & 4 & 0.36 \\
\hline Gastrointestinal tract & Imperforated Anus & 13 & 12 & 13 & 3 & 41 & 3.67 \\
\hline \multirow[t]{4}{*}{$(6.4 \%)$} & Esophageal atresia & 7 & 5 & 3 & 2 & 17 & 1.52 \\
\hline & Duodenal atresia & 2 & 3 & 1 & 0 & 6 & 0.54 \\
\hline & Anal stenosis & 2 & 1 & 0 & 0 & 3 & 0.27 \\
\hline & Ileal stenosis & 0 & 1 & 0 & 0 & 1 & 0.09 \\
\hline Abdominal wall defects & Omphalocele & 9 & 10 & 0 & 1 & 20 & 1.79 \\
\hline \multirow[t]{3}{*}{$(3.0 \%)$} & Diaphragmatic anomalies & 0 & 4 & 1 & 1 & 6 & 0.54 \\
\hline & $\begin{array}{l}\text { Rectus abdominus } \\
\text { diastasis }\end{array}$ & 1 & 3 & 1 & 1 & 6 & 0.54 \\
\hline & Gastroschisis & 2 & 1 & 0 & 1 & 4 & 0.36 \\
\hline Others & Redundant skin at the neck & 3 & 2 & 9 & 9 & 23 & 2.06 \\
\hline \multirow[t]{4}{*}{$(6.0 \%)$} & Nevus & 7 & 7 & 0 & 0 & 14 & 1.25 \\
\hline & Hemangioma & 9 & 3 & 1 & 0 & 13 & 1.16 \\
\hline & Supernumerary nipple & 3 & 6 & 1 & 0 & 10 & 0.90 \\
\hline & Pterigium colli & 3 & 3 & 0 & 1 & 7 & 0.63 \\
\hline TOTAL§ & & 466 & 391 & 163 & 97 & 1117 & \\
\hline
\end{tabular}

$\S$ Total number of cases includes cases not shown in table. 
Colombia and Venezuela did not in the initial analysis. In the secondary analysis with grouping by periods of time, the Poisson regression showed no statistically significant increase or reduction in prevalence. Results per country showed a statistically significant increase in Uruguay and Venezuela in different periods of time during the study period Table-3. Uruguay showed the longest period of significant increase over time. On the other hand, Argentina was the only country with a trend towards reduction since 1992.

After excluding glanular cases, there was no significant increase or reduction in prevalence glo- bally during the study period. Trends by country showed a reduction or increase in prevalence during different periods Table- 4 . The most significant changes were in Uruguay where an $80 \%$ reduction was recorded between 2002 and 2011.

\section{DISCUSSION}

The present study provides epidemiological evidence that over the past two decades there has been an increase in hypospadias prevalence in different countries in South America and at different

Table 3 - Results from adjusted regression models evaluating temporal changes in the prevalence of total hypospadias from 1982 to 2011 in six countries of South America.

\begin{tabular}{|c|c|c|c|c|c|c|c|}
\hline \multirow[b]{2}{*}{ Country ${ }^{1}$} & & \multicolumn{6}{|c|}{ Period } \\
\hline & & $1982-1986$ & $1987-1991$ & $1992-1996$ & 1997- 2001 & $2002-2006$ & $2007-2011$ \\
\hline \multirow[t]{3}{*}{ ARG } & IRR & 1.0 & 0.93 & 0.75 & 0.84 & 0.74 & 0.60 \\
\hline & $95 \% \mathrm{Cl}$ & (Ref.) & $(0.74-1.16)$ & $(0.62-0.92)$ & $(0.71-1.00)$ & $(0.58-0.95)$ & $(0.37-0.98)$ \\
\hline & $P$ & - & 0.501 & 0.005 & 0.055 & 0.016 & 0.039 \\
\hline \multirow[t]{3}{*}{ BRZ } & IRR & 1.0 & 0.97 & 1.03 & 1.10 & 1.05 & 0.90 \\
\hline & $95 \% \mathrm{Cl}$ & (Ref.) & $(0.73-1.29$ & $(0.72-1.48)$ & $(0.79-1.54)$ & $(0.79-1.38)$ & $(0.66-1.22)$ \\
\hline & $P$ & - & 0.830 & 0.871 & 0.583 & 0.750 & 0.489 \\
\hline \multirow[t]{3}{*}{$\mathrm{CHL}$} & IRR & 1.0 & 0.86 & 0.88 & 0.76 & 0.89 & 0.96 \\
\hline & $95 \% \mathrm{Cl}$ & (Ref.) & $(0.52-1.41)$ & $(0.54-1.44)$ & $(0.58-1.00)$ & $(0.64-1.23)$ & $(0.73-1.25)$ \\
\hline & $P$ & - & 0.545 & 0.617 & 0.054 & 0.476 & 0.770 \\
\hline \multirow[t]{3}{*}{$\mathrm{COL}$} & IRR & 1.0 & 0.83 & 1.05 & 1.63 & 0.93 & 0.76 \\
\hline & $95 \% \mathrm{Cl}$ & (Ref.) & $(0.30-2.31)$ & $(0.26-4.16)$ & $(1.33-2.08)$ & $(0.61-1.40)$ & $(0.42-1.36)$ \\
\hline & $P$ & - & 0.798 & 0.018 & 0.166 & 0.403 & 0.348 \\
\hline \multirow[t]{3}{*}{ URU } & IRR & 1.0 & 1.37 & 1.15 & 1.55 & 1.67 & 1.92 \\
\hline & $95 \% \mathrm{Cl}$ & (Ref.) & $(0.92-2.04)$ & $(0.65-2.06)$ & $(1.09-2.19)$ & $(0.98-2.85)$ & $(1.16-3.18)$ \\
\hline & $P$ & - & 0.120 & 0.627 & 0.015 & 0.058 & 0.011 \\
\hline \multirow[t]{3}{*}{ VEN } & IRR & 1.0 & 1.16 & 1.67 & 1.01 & 1.12 & 1.58 \\
\hline & $95 \% \mathrm{Cl}$ & (Ref.) & $(0.88-1.52)$ & $(1.30-2.14)$ & $(0.74-1.37)$ & $(1.04-1.19)$ & $(1.49-1.67)$ \\
\hline & $P$ & - & 0.294 & $<0.001$ & 0.935 & $<0.001$ & $<0.001$ \\
\hline \multirow[t]{3}{*}{ TOTAL } & IRR & 1.0 & 0.98 & 0.99 & 1.02 & 0.99 & 0.93 \\
\hline & $95 \% \mathrm{Cl}$ & (Ref.) & $(0.83-1.16)$ & $(0.81-1.21)$ & $(0.85-1.22)$ & $(0.84-1.16)$ & $(0.75-1.14)$ \\
\hline & $P$ & - & 0.847 & 0.931 & 0.869 & 0.893 & 0.485 \\
\hline
\end{tabular}

${ }^{1}$ Countries: $\mathbf{A R G}=$ Argentina; $\mathbf{B O L}=$ Bolivia; $\mathbf{B R Z}=$ Brazil; $\mathbf{C H L}=$ Chile; $\mathbf{U R U}=$ Uruguay; VEN = Venezuela; $\mathbf{I R R}=$ prevalence-rate ratios estimated from Poisson regression adjusted by hospital compared to the reference period; $\mathbf{9 5} \% \mathbf{C I}=95 \%$ Confidence Interval; $P$ value according the regression model; $\mathbf{N D}=$ no data coverage. 
Table 4 - Number of total births, cases and rates (per 10,000 births) of severe hypospadias by period of time in six countries of South America.

\begin{tabular}{|c|c|c|c|c|c|c|c|c|}
\hline \multirow[b]{2}{*}{ Country ${ }^{1}$} & \multicolumn{8}{|c|}{ Period } \\
\hline & & $1982-1986$ & $1987-1991$ & $1992-1996$ & $1997-2001$ & $2002-2006$ & $2007-2011$ & Total \\
\hline \multirow[t]{4}{*}{$A R G$} & Total births (N) & 193.692 & 276.788 & 311.582 & 230.747 & 204.210 & 99.746 & $1,316.765$ \\
\hline & Cases $(\mathrm{N})^{2}$ & 98 & 118 & 123 & 113 & 93 & 39 & 584 \\
\hline & Rate $^{3}$ & 5.1 & 4.3 & 3.9 & 4.9 & 4.6 & 3.9 & 4.4 \\
\hline & $95 \% \mathrm{Cl}$ & $(4.1-6.2)$ & $(3.5-5.1)$ & $(3.3-4.7)$ & $(4.0-5.9)$ & $(3.7-5.6)$ & $(2.8-5.3)$ & $(4.1-4.8)$ \\
\hline \multirow[t]{4}{*}{ BRZ } & Total births (N) & 235.217 & 204.756 & 193.227 & 161.080 & 185.003 & 130.900 & $1,110.183$ \\
\hline & Cases $(\mathrm{N})^{2}$ & 225 & 162 & 220 & 240 & 284 & 176 & 1.307 \\
\hline & Rat $^{3}$ & 9.6 & 7.9 & 11.4 & 14.9 & 14.8 & 13.2 & 11.7 \\
\hline & $95 \% \mathrm{Cl}$ & $(8.4-10.9)$ & $(6.7-9.2)$ & $(9.9-13.0)$ & $(13.1-16.9)$ & $(13.1-16.7)$ & $\begin{array}{c}(11.3- \\
15.3)\end{array}$ & $(11.0-12.3)$ \\
\hline \multirow[t]{4}{*}{$\mathrm{CHL}$} & Total births (N) & 48.130 & 85.278 & 69.042 & 117.328 & 149.650 & 70.318 & 539.746 \\
\hline & Cases $(\mathrm{N})^{2}$ & 31 & 38 & 45 & 59 & 56 & 20 & 249 \\
\hline & Rate3 & 6.4 & 4.5 & 6.5 & 5.0 & 3.7 & 2.7 & 4.6 \\
\hline & $95 \% \mathrm{Cl}$ & $(4.4-9.1)$ & $(3.1-6.1)$ & $(4.8-8.7)$ & $(3.8-6.5)$ & $(2.8-4.9)$ & $(1.6-4.2)$ & $(4.0-5.2)$ \\
\hline \multirow[t]{4}{*}{ COL } & Total births (N) & 11.672 & 14.762 & 9.571 & 2.286 & 48.308 & 33.116 & 119.715 \\
\hline & Cases $\left(\mathrm{N}^{2}\right.$ & 12 & 10 & 5 & 4 & 36 & 21 & 88 \\
\hline & Rate $^{3}$ & 10.3 & 6.8 & 5.2 & 17.5 & 6.2 & 6.0 & 6.8 \\
\hline & $95 \% \mathrm{Cl}$ & $(5.3-18.0)$ & $(3.2-12.5)$ & $(1.7-12.1)$ & $(4.8-44.8)$ & $(4.2-8.9)$ & $(3.7-9.3)$ & $(5.4-8.4)$ \\
\hline \multirow[t]{4}{*}{ URU } & Total births (N) & 52.476 & 54.050 & 25.831 & 59.397 & 19.573 & 3.810 & 215.137 \\
\hline & Cases $\left(\mathrm{N}^{2}{ }^{2}\right.$ & 23 & 24 & 4 & 21 & 6 & 1 & 79 \\
\hline & Rate $^{3}$ & 4.3 & 4.4 & 1.5 & 3.5 & 3.1 & 2.6 & 3.7 \\
\hline & $95 \% \mathrm{Cl}$ & $(2.8-6.6)$ & $(2.9-6.6)$ & $(0.4-3.9)$ & $(2.2-5.4)$ & $(1.1-6.7)$ & $(0.1-14.6)$ & $(2.9-4.6)$ \\
\hline \multirow[t]{4}{*}{ VEN } & Total births (N) & 54.036 & 78.084 & 84.782 & 68.686 & 93.605 & 28.532 & 407.725 \\
\hline & Cases $(\mathrm{N})^{2}$ & 34 & 33 & 44 & 22 & 45 & 40 & 218 \\
\hline & Rate $^{3}$ & 6.3 & 4.2 & 5.2 & 3.2 & 4.8 & 14.0 & 5.3 \\
\hline & $95 \% \mathrm{Cl}$ & $(4.4-8.8)$ & $(2.9-5.9)$ & $(3.8-7.0)$ & $(2.0-4.8)$ & $(3.5-6.4)$ & $\begin{array}{c}(10.0- \\
19.1)\end{array}$ & $(4.7-6.1)$ \\
\hline
\end{tabular}

${ }^{1}$ Countries: $\mathbf{A R G}=$ Argentina; $\mathbf{B O L}=$ Bolivia; $\mathbf{B R Z}=$ Brazil; $\mathbf{C H L}=$ Chile; $\mathbf{U R U}=$ Uruguay; $\mathbf{V E N}=$ Venezuela; $\mathbf{I R R}=$ prevalence-rate ratios estimated from Poisson regression adjusted by hospital compared to the reference period; $\mathbf{9 5} \% \mathbf{C I}=95 \%$ Confidence Interval; $P$ value aording the regression model.

points in time. This finding is consistent with reports from other parts of the World. To our knowledge, our analysis is one of few large-scale studies to specifically focus on the Latin American population, and is particularly valuable given the limited information in our region (13). The global prevalence reported herein (11.3/10.000 newborns) is very similar to other studies worldwide $(9,14,15)$. In agreement with data reported by Palouzzi et al., showing an increase in prevalence in the United States during a similar period of time, we also detected an increase in prevalence in South America. A similar trend was recently reported in Sweden (16).

Importantly, the ECLAMC database includes distal hypospadias cases in the analysis (15-17), this provides a more accurate picture of the true prevalence of the condition. Also, the methodology of a standardized physical examination on all newborns for every involved center reduces the probability of over-diagnosis. Surprisingly, in stark contrast with other studies such as the Metropolitan Atlanta Congenital Birth Defects Program (MACDP), we did not detect an increase in more severe hypospadias cases over time in the global analysis, and noticed that 
the trends favored higher prevalence at the expense of distal defects. Our detection procedure remained the same throughout the study confirming that these results are not a result of detection bias.

Other reports from developed countries have found an increase in prevalence of hypospadias of 1 to $4 \%$, consistent with our increase of 3.3\% (18). We acknowledge that an argument could be made for our findings being subject to artifact triggered by better reporting over time; however, the nature of our methodology dramatically reduced this potential bias. Nonetheless, the secondary analysis excluding glanular cases failed to support the initially detected increase. Specific regions showed an increase or reduction in prevalence. Given the latter there are important characteristics that deserve further evaluation, including the impact of industrialization, environmental pollution with different chemicals, and degree of urbanization in different regions with significant changes in prevalence. Our future studies will evaluate geographical and regional differences according to the secondary analysis results. It is interesting to highlight the different trends detected for different South American countries, raising the possibility of differences in socioeconomics and industrialization as an explanation for the reported trends. This hypothesis is supported by results from other studies, such as that of Li et al., who found that the global increase in prevalence in China was more evident in urban areas $(19,20)$.

The severity distribution in this report is consistent with previous literature, with a similar breakdown and predominance of distal hypospadias cases. Similarly, we corroborate literature that indicates an association between proximal hypospadias defects and other associated anomalies. For example, Leung et al. established that 20\% of patients with hypospadias had other associated anomalies, similar to our results (20). Our data is novel in terms of exploring the degree of this association. For glanular and coronal hypospadias, we found no statistically significant results, whereas for penile and scrotal hypospadias we noted a positive association, with a gradient in favor of anomalies being more prevalent for the most proximal hypospadias defects. Some anomalies share similar molecular mechanisms that may explain their co-occurrence. A literature review on this topic provided little information. For instance, there are no reported associations between cleft lip/ palate and hypospadias in the OMIM database, and many other studies have failed to detect links herein described between specific anomalies and proximal hypospadias. Although far from being conclusive and in clear need of further study, the information provided sets the basis for future studies specifically focusing on the presence of multiple anomalies in children with genitourinary congenital defects.

There are important shortcomings and limitations that deserve acknowledgement in the present study. We accept that the methodology employed is sub-optimal, as it did not include the entire population at risk (i.e. all male newborns in each country), leaving proportions of the population out of the analysis. Nevertheless, the surveillance protocol was strictly enforced, allowing us to capture information on a substantial number of babies over a long period of time. In addition, as previously mentioned, our findings may be driven by better detection compared to other surveillance systems, which conceptually can systematically favor good detection. Although plausible, the reported worldwide trends support the possibility of an increase in prevalence that has previously been reported for this large continental region but limited to specific regions for short periods of time.

Hospital-based sources of information may limit the final prevalence trend analysis due to differences in surveillance between centers during the study period. We tried to overcome this limitation with the secondary analysis. Lastly, it could be argued that the number of cases reported in this study could be biased due to detection in referral centers 
dealing with high-risk pregnancies. This, however, was not the case, as the included healthcare institutions were busy general hospitals.

Despite these perceived limitations, we propose that our results have value given the standardized way that the data was collected and that the study was conducted during the entire period. All included centers provided uninterrupted surveillance of their patients during their participation in the study, and centers with missing information were excluded to improve the quality of our results. Ultimately, this information supports prevalence patterns described in the literature but the secondary analysis made it difficult to conclude that there has been a clear increase in this previously under-evaluated part of the world.

\section{CONCLUSIONS}

Our study is unique given the large geographical region, the study period, and sample size analyzed. We identified an increasing trend in hypospadias prevalence supported by a standardized methodology in specific regions and periods and novel information about associated congenital anomalies. However, subsequent analysis failed to find evidence supporting a global increase, particularly when severe hypospadias were selectively analyzed. Further studies are needed in order to determine whether environmental factors might be involved in specific regions.

\section{ABBREVIATIONS}
$\mathrm{ABD}=$ Abdominal wall
$\mathrm{CNS}=$ Central nervous system
$\mathrm{CV}=$ Cardiovascular

ECLAMC = Latin-American Collaborative Study of Congenital Malformations

$\mathrm{FA}=$ Facial anomalies

GIT $=$ Gastrointestinal tract

GUT $=$ Genitourinary tract

$\mathrm{IH}=$ Isolated hypospadias

NIH = Non-isolated hypospadias

\section{CONFLICT OF INTEREST}

None declared.

\section{REFERENCES}

1. Fernández N, Henao-Mejía J, Monterrey P, Pérez J, Zarante I. Association between maternal prenatal vitamin use and congenital abnormalities of the genitourinary tract in a developing country. J Pediatr Urol. 2012;8:121-6.

2. Zarante I, Franco L, López C, Fernández N. Frequencies of congenital malformations: assessment and prognosis of 52,744 births in three cities of Colombia. Biomedica. 2010;30:65-71.

3. Colborn T, vom Saal FS, Soto AM. Developmental effects of endocrine-disrupting chemicals in wildlife and humans. Environ Health Perspect. 1993;101:378-84.

4. Dolk H, Loane M, Garne E. The prevalence of congenital anomalies in Europe. Adv Exp Med Biol. 2010;686:349-64. 
5. Paulozzi LJ, Erickson JD, Jackson RJ. Hypospadias trends in two US surveillance systems. Pediatrics. 1997;100:831-4.

6. Agopian AJ, Lupo PJ, Canfield MA, Langlois PH. Case-control study of maternal residential atrazine exposure and male genital malformations. Am J Med Genet A. 2013;161A:977-82.

7. Sharpe RM. Pathways of endocrine disruption during male sexual differentiation and masculinization. Best Pract Res Clin Endocrinol Metab. 2006;20:91-110.

8. Monteleone Neto R, Castilla EE, Paz JE. Hypospadias: an epidemiological study in Latin America. Am J Med Genet. 1981;10:5-19

9. Castilla EE, Orioli IM. ECLAMC: the Latin-American collaborative study of congenital malformations. Community Genet. 2004;7:76-94.

10. Kalfa N, Sultan C, Baskin LS. Hypospadias: etiology and current research. Urol Clin North Am. 2010;37:159-66.

11. Fleiss J, Levin B, Chao Paik M. Statistical methods for rates and proportions, 3rd edition. John Wiley and sons, 2003; pp. 192.

12. Monlleó IL, Zanotti SV, Araújo BP, Cavalcante EF Jr, Pereira PD, Barros PM, et al. Prevalence of genital abnormalities in neonates. J Pediatr (Rio J). 2012;88:489-95.

13. [No authors]. International Clearinghouse for birth defects surveillance and research annual report 2010 (with data for 2008) Available at. http://www.icbdsr.org/filebank/documents/ ar2005/Report2010.pdf.

14. Källén B. Case control study of hypospadias, based on registry information. Teratology. 1988;38:45-50.

15. Nordenvall AS, Frisén L, Nordenström A, Lichtenstein $P$,
Nordenskjöld A. Population based nationwide study of hypospadias in Sweden, 1973 to 2009: incidence and risk factors. J Urol. 2014;191:783-9.

16. Lund L, Engebjerg MC, Pedersen L, Ehrenstein V, Nørgaard M, Sørensen HT. Prevalence of hypospadias in Danish boys: a longitudinal study, 1977-2005. Eur Urol. 2009;55:1022-6. Erratum in: Eur Urol. 2009;56:e41.

17. Gallentine ML, Morey AF, Thompson IM Jr. Hypospadias: a contemporary epidemiologic assessment. Urology. 2001;57:788-90.

18. Li Y, Mao M, Dai L, Li K, Li X, Zhou G, et al. Time trends and geographic variations in the prevalence of hypospadias in China Birth Defects Res A Clin Mol Teratol. 2012;94:36-41.

19. Oliva A, Biasatti R, Cloquell S, González C, Olego S, Gelin A. [ls there any relationship between rural environmental factors and reproductive health in the Pampa Humeda in Argentina?]. Cad Saude Publica. 2008;24:785-92.

20. Leung TJ, Baird PA, McGillivray B. Hypospadias in British Columbia. Am J Med Genet. 1985;21:39-50.

Correspondence address:

Nicolás Fernández, MD, PhD

Pontificia Universidad Javeriana Hospital Universitario San Ignacio

Ak. 7 \# 19141

Bogotá, Colômbia

Telephone:+57 5 944-6161

E-mail: fernandez.j@javeriana.edu.co 